\title{
Kinema Studio Lighting
}

In another column is published the Interim Report of the Committee on the Causes and Prevention of Blindness regarding the alleged dangerous lights used in kinema studios. Readers will remember that a question was asked upon the subject in the House of Commons and that it was referred by the Minister of Health to the Committee in question. The Committee's report is most reassuring. It was shown by witnesses that the inflammation of the eyes was merely transitory, occurring within a few hours of leaving the studio, and speedily subsiding. No evidence was obtained that the inflammation was ever permanent or serious. As regards this country practically all complaints of which the Committee have heard date from the last three months of 1920, and coincided with the introduction and injudicious use of certain very powerful arc lamps of the searchlight type, largely imported from America. The evidence went to show that injuries to the eyes have occurred in kinema studios from the use of unscreened arc lights, that no injury has occurred from the use of adequately screened arc lamps, and finally that the use of unscreened arc lights in these studios is not necessary.

The Committee thinks that the eye trouble is due to the unimpeded access of ultra-violet rays to the eyes. The Committee is definitely of the opinion that the employment of suitably enclosed and screened arc lights is not likely to be dangerous to the eyes apart from culpable temerity on the part of the artistes.

\section{COMMITTEE ON THE CAUSES AND PREVENTION} OF BLINDNESS

\section{Interim Report regarding alleged dangerous lights in Kinema Studios.}

To the Rt. Hon. Sir Alfred Mond, Bart., M.P., SIR, Minister of Health.

We have the honour to present the following Interim Report :-

During the last three months of 1920 , complaints were made to the Actors' Association by actors and actresses working in kinematograph studios, of injury to the eyes, caused by intense lights used for the production of films in these studios. A question on this subject was asked in the House of Commons, and the Minister of Health referred the matter to the Committee on the Causes and Prevention of Blindness for consideration and report.

We have inquired into the question, taking evidence as to 